\title{
Materials and techniques for indirect restorations and prosthodontics
}

Contemporary dental practice in the UK: indirect restorations and fixed prosthodontics P. A. Brunton, G. J. Christensen, S. W. Cheung, F. J. T. Burke, and N. H. F. Wilson Br Dent J 2005; 198: 99-103

\section{Objectives}

To investigate, by questionnaire, the use and selection of materials and techniques for indirect restorations and fixed prosthodontics by dental practitioners in the North West of England and Scotland.

\section{Methods}

A questionnaire was sent to 1,000 general dental practitioners selected at random from dentists in Scotland and the North West of England. Non-responders were sent another questionnaire after a period of 4 weeks had elapsed.

Results

A total of 701 usable questionnaires were returned, giving a response rate of $70 \%$. When selecting a material for the core build-up of vital teeth practitioners used the following materials (\%): amalgam (60), dual and light-cured resin composite (54), glass-ionomer cements (47), compomer (29) and resin-modified glass-ionomer cements (24). Where the use of a post was indicated indirect posts of both precious (67) and non-precious (37) alloys were preferred to prefabricated posts by the majority of practitioners for the restoration of root filled teeth. Direct titanium (14) and stainless steel (14) posts were not used extensively. Impression materials used by the practitioners were as follows: additioncured silicone (70), condensation-cured silicone (20), polyether (9) and polysulphide (2). Traditional glass-ionomer cements (59) were used for the luting of single and multiple porcelain fused to metal units, with zinc phosphate and polycarboxylate cements (33) being the preferred alternatives.

\section{Conclusions}

The majority of the practitioners surveyed in this study used: amalgam for core build-ups; indirect posts; addition-cured silicone for impressions; and glass-ionomer cements for luting procedures.

\section{IN BRIEF}

- Amalgam continues to be preferred for core build-ups.

- Despite their disadvantages dentine pins are still widely used.

- Laminate veneers are preferred by younger practitioners for the restoration of anterior teeth.

- All-ceramic crowns are prescribed occasionally and a significant number of practitioners do not prescribe them.

- For inlay/onlay type restorations, ceramic is the preferred material and there is considerable uncertainty about which material to use for these restorations.

\section{COMMENT}

This paper is the last in a series of three papers investigating aspects of general dental practice by a questionnaire survey of GDPs in the North West of England and Scotland. Seven hundred and one out of a sample size of 1,000 GDPs responded to the extensive questionnaire.

The increasing number of adults retaining their teeth into old age and the increased demand for fixed rather than removal prostheses has stimulated a proliferation of techniques and materials that practitioners can choose from to provide care for their patients. The aim of the study was to investigate the use and selection of materials and techniques for indirect restorations and fixed prosthodontics.

This study showed, not surprisingly, that there was a wide variation in the materials used for core build-ups in vital teeth, with GDPs choosing mainly amalgam or resin composite depending on the clinical situation. The relevance of the significant finding in this study of gender differences and the choice of material for core build-ups is difficult to understand. What is possibly more relevant is the undergraduate teaching and postgraduate learning that the respondent practitioners had undergone on this aspect of clinical treatment. This could be an area for further research.

Another finding was the wide variation in the type of post and core systems used for the restoration of non-vital teeth. Although the authors suggest that there is a movement away from the use of cast posts to the direct placement of prefabricated posts and direct core build-ups, the evidence is inconclusive. ${ }^{1}$ Practice based longitudinal research in this area might provide the necessary evidence.

It was reassuring to find that the majority of practitioners used addition cured silicone impression materials for crown and bridge work. The choice of luting cements was varied with the majority choosing glass-ionomer cements and a significant number also using polycarboxlate and zinc phosphate cements. Because of the limitations of this study the reasons for these choices were not investigated, particularly with regard to the undergraduate and postgraduate education experiences of the respondents. This study is useful in that it has also highlighted areas of research and education with regard to the influential factors in crown selection and tooth coloured inlays and onlays.

In conclusion, this paper has shown the importance and the need for good quality general practice based research to provide the evidence for dentists to provide appropriate care to patients.

N. Palmer, General Dental Practitioner,

Crosby, Liverpool

doi:10.1038/sj.bdj.4811978

1. Ellner S, Bergendal T, Bergman B. Four post-and-core combinations as abutments for fixed single crowns: a prospective up to 10-year study. Int J Prosthodont 2003: 16: 249-254. 